\section{UK EXPERIMENTS Results raise questions \\ The teams behind three UK geoengineering studies have reported decidedly mixed results. \\ Matthew Watson, a volcanologist at the University of Bristol, presented the results of the Stratospheric Particle Injection for Climate Engineering (SPICE) project. SPICE investigated whether spraying particles into the atmosphere could reflect sunlight and cool the planet, offsetting global warming. A planned test of some of the technology was abandoned in 2012 when conflict-of-interest issues emerged over a patent application for the system. But Watson says that SPICE produced useful insights, such as how a large-scale project might alter the Sahel region in Africa. \\ Piers Forster at the University of Leeds, who led the Integrated Assessment of Geoengineering Proposals project, said that his team's computer modelling showed that several techniques to manage the Sun's radiation would produce damaging changes in rainfall that could affect $25-65 \%$ of the world's population. \\ Watson, Forster and the University of Oxford's Steve Rayner, who is leader of a third effort called the Climate Geoengineering Governance project, agreed that their work created many questions. Daniel Cressey}

that little funding is available for further studies. "We're caught up in politics," says Ken Buesseler, an ocean scientist at Woods Hole Oceanographic Institution in Massachusetts. "You'd absolutely like to avoid rogue experiments that don't generate proper science. But there is every reason to pursue real science in the field in an open and responsible way."

Meeting discussions are aimed at creating comprehensive guidelines for the safe conduct of field experiments.

Neither ocean fertilization nor any other single activity will solve the global warming problem, cautions Anya Waite of z the Alfred Wegener Institute in Bremerhaven, Germany, who represents the fields of oceanography and limnology at this week's meeting. "But limited oceanfertilization experiments are telling us a lot about how biological processes in the ocean control climate. In terms of new regulations, they should be the first $\mathrm{cab}$ off the ranks." - SEEEDITORIALP.8

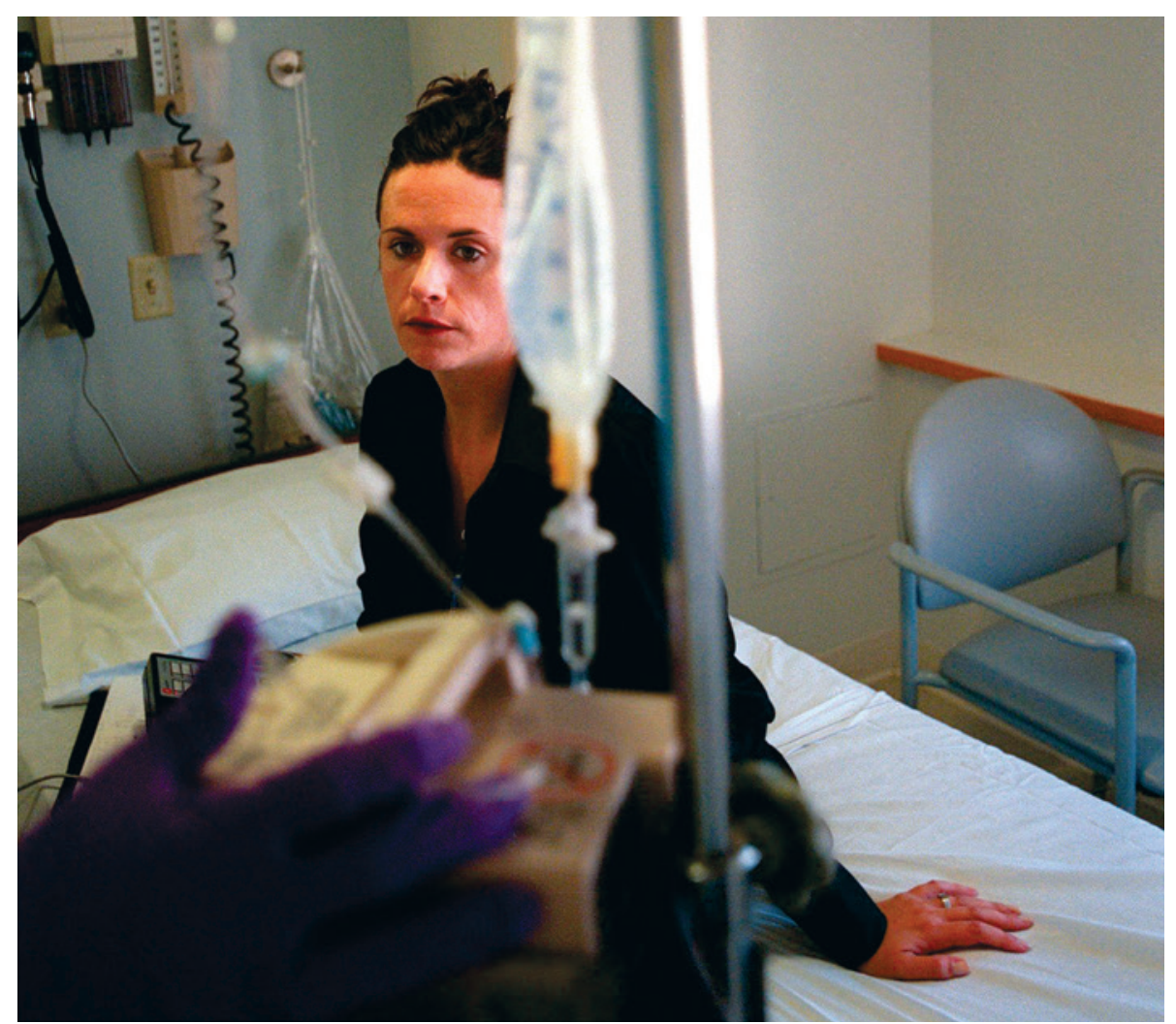

People with cancer often receive drugs that are not yet approved for their specific diagnosis.

MEDICAL RESEARCH

\title{
Projects seek hidden effects of cancer drugs
}

\section{Researchers gather data on innovative uses of cancer treatments.}

\section{BY HEIDI LEDFORD}

$\mathrm{M}$ ore than $60 \%$ of US prescriptions for cancer drugs call for using the medicines in ways that are not approved by the government. Often, they are the only hope against a fatal illness that has thwarted conventional treatments. But although such 'off-label' use is common, it is hard to know how effective it is because outcomes are not being tracked systematically.

Thousands of small-scale experiments are going on all the time in clinics and hospitals - but, says Amy Abernethy, an oncologist at Duke University in Durham, North Carolina, "we haven't been able to learn from them".

On 21 November, researchers gathering in Washington DC for the annual Conference

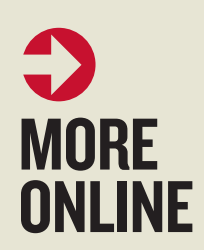

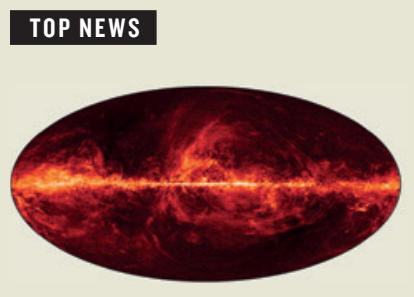

Planck probe dashes dark-matter hopes go.nature.com/vgszc3

\section{MORE NEWS}

- How humans see infrared light go.nature.com/slblpx

- Graphene makes sieve for hydrogen fuel cells go.nature.com/ cpxybh

- How EU budget impasse imperils science go.nature.com/ wfaadh 
- on Clinical Cancer Research discussed two programmes, both planned for launch next year, that will aim to capture data from a subset of those experiments. The intent is to provide databases for researchers to mine - looking not just for potentially effective treatments, but also for cellular clues as to why individual cancers are resistant or susceptible to drugs.

"It's going to be what we learn from our patients that leads us back to understanding the cancer biology," says Vincent Miller, chief medical officer of Foundation Medicine, a company in Cambridge, Massachusetts, that provides genetic profiles of tumours.

Although it is legal for physicians to prescribe drugs off-label in the United States, such use is often controversial, and drug-makers pay steep fines if they promote their products for unapproved uses.

\section{STANDARD PRACTICE}

Off-label drug regimens are woven into the fabric of cancer care and are expected to become more prevalent as treatments become more tailored to the genetics of individual tumours. But genetics is not everything: drugs can be approved only for the cancers in which they have been tested, even if the mutation that they target is shared by several tumour types. Vemurafenib and dabrafenib, for example,

target a mutation in a protein called BRAF. They have been approved to treat melanoma, but not lung or thyroid cancers that have the same mutation.

The problem is partly one of numbers, says Richard Schilsky, chief medical officer of the American Society of Clinical Oncology (ASCO) in Alexandria, Virginia. "There are not

\section{"It's going to be what we learn from our patients that leads us back to understanding the cancer biology."} enough patients and not enough money to test every drug in every subtype of cancer using a randomized clinical trial," he says.

To address this shortcoming, Schilsky is spearheading a programme called the TAPUR (Targeted Agent and Profiling Utilization Registry) Study, to be launched in mid-2015. The study, run through ASCO, will compile information about treatments, outcomes and mutations in people who have exhausted conventional therapies and moved on to unapproved treatments.

A similar effort, led by Dane Dickson, director of clinical science for molecular diagnostics at the health benefits provider Palmetto of Columbia, South Carolina, has brought together pharmaceutical companies, researchers and patient advocates to launch another registry that aims to capture data about off-label use. The programme, called MED-C (Molecular Evidence Development Consortium), will require every person who enrols to undergo a standardized genetic test so that researchers can better compare results from different hospitals.

Both programmes are in discussions with pharmaceutical companies to help to provide therapies free-of-cost to participants. This is intended to motivate physicians to participate. In exchange, the companies have an opportunity to gather more data about their drugs.

The benefit for patients is clear, says Ellen Sigal, chairwoman and founder of Friends of Cancer Research, an advocacy group based in Washington DC, which co-hosted the conference with the Brookings Institution, a nearby think-tank. "Off-label use is happening and we'd better figure out a way to get the data and do it in a meaningful way," she says. "Right now, we are getting nothing."

\section{CORRECTION}

The World View 'Open access is tiring out peer reviewers' (Nature 515, 467; 2014), erroneously calculated the percentage rise in the number of articles indexed in Scopus as $213 \%$. In fact, the increase is $113 \%$. 